ЩИТОВА Н.А. ${ }^{*}$, Северо-Кавказский федеральный университет,

СОЛОВЬЕВ И.А., г. Ставрополь, Россия

БЕЛОЗЕРОВ В.С. * * stavgeo@mail.ru

\title{
ДАГЕСТАН: МОДЕЛЬ МЕЖКУЛЬТУРНОГО ВЗАИМОДЕЙСТВИЯ В ПОЛИЭТНИЧНОМ РЕГИОНЕ*
}

Введение:

Материалы и методы исследования:

Обсуждение результатов

В последние десятилетия в России резко актуализировалась проблема межэтнических отношений. Дагестан, как один из наиболее пестрых в этнокультурном отношении регионов России, представляет особый интерес для изучения межэтнической среды. Цель исследования - проанализировать направления современных этнических процессов в Дагестане и выявить основные межэтнические проблемы.

исследования

Статья подготовлена на основе материалов полевых исследований, проведенных авторами в 2018 г. Основными инструментами исследования явились массовое интервьюирование местного населения, экспертные опросы представителей властных структур, интеллигенции, научного и бизнес-сообществ, а также визуальные наблюдения. Полученные в ходе полевых исследований отдельные данные корреспондировались с данными официальной статистики. В исследовании был применен метод ключевых территорий.

Главным рефреном всех опросов является суждения населения об отсутствии в Дагестане межэтнических проблем и невозможности возникновения межэтнических противостояний, что подтверждается отсутствием ксенофобских настроений, распространением практик толерантного поведения, позитивные установки по поводу межэтнических браков. Одновременно прослеживается сохранение этнического самосознания и отвергается идея межэтнической консолидации и формирования единой дагестанской нации. В полиэтничных городских сообществах развиваются интеграционные межэтнические процессы, и формируется городская идентичность. Установлено два вида интеграционных моделей.

Выводы: $\quad$ Результаты исследования свидетельствуют о формировании в Дагестане своеобразной полиэтничной системы, находящейся в стадии достаточно равновесного этнокультурного состояния. Этнические процессы проявляются в виде внутриэтнических дезинтеграции на локальные поселенческие общности. В больших городах явно выражены интеграционные тенденции и распространение городских форм идентичности.

Ключевые слова: Республика Дагестан, межэтнические отношения, социологический опрос, поселенческая локальная идентичность, субэтническиая группа, интеграционные модели, религиозность, этнические проблемы.

Исследование выполнено в рамках гранта РФФИ 16-06-00179 «Разработка и апробация системы геоинформационного мониторинга этнодемографических процессов (на примере регионов Северного Кавказа)». 
$\begin{array}{ll}\text { Schitova N.A. } & \text { North Caucasus Federal University, } \\ \text { Soloviev I.A. } & \text { Stavropol, }\end{array}$

Belozerov V.S. Russia

\section{Dagestan - a model of intercultural interaction in a polyethnic region}

Introduction: $\quad$ The recent decades Russia has seen a sharp rise in the issue involving interethnic relations. Dagestan, as one of Russia's most diverse regions from the ethnic \& cultural stance, is of particular interest when it comes to studying the interethnic environment. The purpose of this study is to analyze the course of the ethnic processes that are underway in Dagestan nowadays, and to identify the major interethnic issues.

Materials and methods: The article is based on the data from field research carried out in 2018. The main research tools included interviews among the local population, expert surveys involving the authorities, intellectuals, scientific and business communities, as well as visual observations. The individual data obtained through the fieldwork were compared to the official statistics. The study involved the method of key territories.

Discussion: $\quad$ The major feature through all the polls was the opinion expressed by the local population stating there are no interethnic issues in Dagestan and no potential grounds for any interethnic confrontation, which is confirmed through lack of any xenophobic attitudes, the spread of tolerant practices, and positive attitudes towards interethnic marriages. At the same time, it is obvious that ethnic identities can be traced clearly along with the idea rejecting interethnic consolidation and the development of a single Dagestan nation. Polyethnic urban communities reveal interethnic processes going on as well as the formation of an urban identity. Two types of integration models have been identified.

Conclusions: $\quad$ The outcomes of the study reveal the development of a specific polyethnic system shaping in Dagestan, whereas the system remains rather balanced ethnically \& culturally. The ethnic processes reveal themselves through internal ethnic disintegration in local communities. Larger urban areas demonstrate clear integration trends and the spread of urban types of identity.

Keywords: $\quad$ Republic of Dagestan, interethnic relations, sociological survey, local settlement identity, subethnic group, integration models, religiosity, ethnic problems.

\section{Введение}

Проблема межнациональных и межконфессиональных отношений приобретает в начале XXI в. особую актуальность. Во всем мире идут поиски новых концепший регулирования этнических взаимодействий и эффективных инструментов национальной политики. Актуальность данной проблематики растет и в российской политической повестке дня, подогреваемая эпатажными выступлениями националистически аганжированных деятелей политики и культуры и часто односторонними публикациями в средствах массовой информации, подающими не всегда точные факты без аналитического сопровождения.

Среди российских регионов Республика Дагестан выделяется своей многонациональностью. Кроме крупных по численности этносов здесь проживают большое число малых этнических и субэтнических групп, с разными лингвистическими и культурологическими особенностями [1]. По переписи населения 2010 г. было учтено более 30 этносов, говорящих на дагестанских 
языках. К числу других многочисленных народов республики относятся кумыки, азербайджанцы, русские, ногайцы (табл. 1). Вместе с тем, следует отметить, что материалы переписи дают лишь самое общее представление об этнической структуре населения республики, а точность некоторых данных сомнительна.

Гипотеза нашего исследования состояла в том, что полиэтничность выступает в качестве фактора усложнения сценариев межкультурного и межконфессионального взаимодействия. Таким образом, выбор Дагестана в качестве пилотного региона очевиден. Цель исследования состояла в выявлении основных межэтнических проблем в Республике Дагестан

Таблица 1. ЭТНИЧЕСКАЯ СТРУКТУРА РЕСПУБЛИКИ ДАГЕСТАН

ПО ДАННЫМ ПЕРЕПИСИ $2010 Г$.

Table 1. Ethnic structure of the Republic of Dagestan (census, 2010)

\begin{tabular}{|c|c|c|c|c|c|}
\hline Этносы & $\begin{array}{l}\text { Численность, } \\
\text { чел. }\end{array}$ & $\begin{array}{l}\text { Удельный } \\
\text { вес, \% }\end{array}$ & Субзтносы & $\begin{array}{l}\text { Численность, } \\
\text { чел. }\end{array}$ & $\begin{array}{l}\text { Удельный } \\
\text { вес, \% }\end{array}$ \\
\hline 1. Аварцы & 850011 & 29,2 & 1. Дидойцы" & 11623 & 0,4 \\
\hline 2. Даргинцы & 490384 & 16,8 & 2. Андийцы ${ }^{*}$ & 11448 & 3,9 \\
\hline 3. Кумыки & 431736 & 14,8 & 3. Ахвахцы ${ }^{*}$ & 7923 & 0,3 \\
\hline 4. Лезгины & 385240 & 13,2 & 4. Бежтинцыы & 5956 & 0,2 \\
\hline 5. Лакцы & 161276 & 5,5 & 5. Каратинцы ${ }^{*}$ & 4761 & 0,2 \\
\hline 6. Азербайджанцы & 130919 & 4,5 & 6. Ботлихцы" & 3508 & 0,1 \\
\hline 7. Русские & 104020 & 3,6 & 7. Гунзибцы* & 918 & - \\
\hline 8. Ногайцы & 40407 & 1,4 & 8. Казаки & 688 & - \\
\hline 9. Агулы & 28054 & 1,0 & 9. Тиндалы ${ }^{*}$ & 634 & - \\
\hline 10. Табасараны & 11884 & 0,4 & 10. Хваршины" & 526 & - \\
\hline 11. Рутульцы & 2784 & 0,1 & 11. Гинухцы* & 439 & - \\
\hline 12. Цахуры & 977 & - & 12. Годоберинцы* & 426 & - \\
\hline 13. Горские евреи & 196 & - & 13. Кубачинцы| & 101 & - \\
\hline 14. Таты & 45 & - & 14. Чамалалы" & 16 & - \\
\hline $\begin{array}{l}\text { Другие народы } \\
\text { и лица, не указавшие } \\
\text { национальность }\end{array}$ & 223324 & 7,68 & $\begin{array}{l}\text { 15. Чеченцыы- } \\
\text { аккинцыы }\end{array}$ & 15 & - \\
\hline \multirow[t]{2}{*}{ Bcero } & 2910249 & 100 & 16. Арчинцы" & 6 & - \\
\hline & & & 17. Кайтагцы ${ }^{\star \star}$ & 4 & - \\
\hline
\end{tabular}




\section{Материалы и методы исследования}

Информационной основой данной статьи являются данные официальной статистики и материалы полевых этнографических исследований, проведенных в ходе экспедиции по Дагестану летом 2018 г.

Данное исследование было направлено на анализ индивидуальных мнений, представлений, оценок разных этнических категорий населения, что обусловило необходимость разработки программы конкретного социологического обследования в ключевых территориях. В качестве территорий - ключей были выбраны три города (Кизляр, Махачкала и Дербент), а также сельские политичные поселения Кизлярского района, моноэтничные поселения Гунибского (с преобладанием аварцев), Дахадаевского (с преобладанием даргинцев) и Докузпаринского района (с преобладанием лезгинов). Использовались методы выборочного опроса населения и экспертного опроса. Население опрашивалось методом демоскопического интервью. Интервьюер имел структурированный вопросник, включавший вопросы преимушественно открытого и частично закрытого типа. При беседе интервьюер вовлекал респондента в более откровенный разговор, пытаясь понять истинную точку зрения и получить полные и развернутые ответы по теме исследования, не ограничиваясь рамками вопросника. Это позволило перевести исследование в качественную плоскость и получить представление о глубинных процессах и специфике исследуемой территории. Ответы в опросный лист записывал интервьюер со слов респондента, что позволило при сравнительно небольших объемах выборки повысить достоверность полученной информации. Всего было получено 62 интервью. Среди респондентов были представители разных этнических групп - аварцы, даргинцы (в том числе, кубачинщы), кумыки, лезгины, русские, лакцы, табасараны, азербайджанцы, ногайцы, рутульцы, евреи.

Метод экспертного опроса удачно дополнил результаты опроса населения и позволил установить взаимосвязи между отдельными явлениями и интерпретировать их в контексте общих проблем территории. В качестве экспертов выступили деятели официальной власти - главы или заместители глав городских и сельских администраций, а также представители разных профессий из числа старожильческого населения (начальник отдела казачьего центра, директор школы, музейный работник, экскурсовод, юрист, ученый-регионовед, представитель еврейской религиозной общины, частный предприниматель, студент-политолог). Всего опрошено 13 экспертов. С каждым из них работа велась индивидуально. Опрос проводился в виде личного интервью по заранее составленному сценарию с частичной формализацисй. Содержание интервью записывалось на диктофон или в регистрационный лист.

Поставленные вопросы имели цель выявить влияние полиэтничности на ход социально-экономических процессов, состояние взаимоотношений между людьми разных национальностей, оценку населением уровня этнической напряженности и конфликтогенности в местах проживания, роли этни- 
ческих элит в формировании межнационального климата, состояния национальной политики в республике и стране, понять соотношение между этническим и религиозным сознанием людей.

Отдельная группа вопросов была направлена на установление степени сплоченности регионального социума как целостного организма, действующего во благо своего места жительства - поселения, района, республики.

\section{Обсуждение результатов исследования}

Прежде всего, следует отметить, что в Дагестане сложилась уникальная межэтническая система, в которой причудливо сочетаются интернационализм и сохранение этнокультурной самобытности, что проявляется в следующих процессах:

1. Широкое распространение стратегий толерантного поведения. В разговорной речи отсутствуют некорректные выражения, не артикулируются этнокультурные особенности. На вопрос «Испытываете ли Вы неприятные ощущения, когда в Вашем присутствии говорят на непонятном для Вас языке?» положительно ответили менее $1 \%$ всех респондентов. Наиболее типичное отношение проявилось в ответе: «Дагестан многонациональная республика и понимаю, что выразить мысль при общении на своем языке гораздо легче».

2. Отсутствие бытовых проявлений ксенофобий и этнофобий. 70,4\% респондентов никогда не испытывали пренебрежительное отношение к себе причиной которого являлась национальность, ни в быту, ни на работе, ни в общественной жизни.

3. Личностная установка и готовность к межэтническим контактам в разных сферах взаимодействия. $85,2 \%$ респондентов выразили готовность заводить дружбу, быть соседями, коллегами по работе с представителями других национальностей.

4. Распространение межэтнических браков. Почти половина опрошенных допускают для себя или своих близких возможность вступать в межэтнические браки. 18,5\% имеют реальные брачные отношения с представителями других национальностей, $14,5 \%$ - родились в смешанных браках.

5. Межэтнические проблемы выражены достаточно слабо или носят латентный характер. Большинство респондентов (более $80 \%$ ) указали на их отсутствие в местах проживания, примерно $11 \%$ затруднились ответить на этот вопрос и только 7,4\% считают, что межэтнические обострения случаются изредка. Несколько выше доля лиц $(22,2 \%)$, считающих, что редкие межнациональные проблемы бывают или 
Таблица 2. ЭКСПЕРТНЫЕ МНЕНИЯ О НАЛИЧИИ МЕЖЭТНИЧЕСКИХ ПРОБЛЕМ Table 2. Expert opinion on interethnic problems

\begin{tabular}{|c|c|c|}
\hline № & $\begin{array}{l}\text { Место } \\
\text { интервьюирования }\end{array}$ & Цитаты из интервью \\
\hline 1. & Дербент & $\begin{array}{l}\text { «На уровне молодежи иногда возникают конфрлик- } \\
\text { ты, раньше было часто, сейчас нет...») }\end{array}$ \\
\hline 2. & Кизляр & $\begin{array}{l}\text { «В Дагестане особо нет[межэтнических] проблем, } \\
\text { возле церкви [в Кизляре] был теракт, но он не свя- } \\
\text { зан с конфликтом между этносами. Это была акция } \\
\text { устрашения людей вообще...») }\end{array}$ \\
\hline 3. & Кизляр & $\begin{array}{l}\text { «Никогда не было, и нет. Надеюсь, что не будет. } \\
\text { Воспитание такое, что младшие уважают старших, } \\
\text { и все дружат друг с другом. Теракт (нападение на } \\
\text { прихожан церкви) - это фанатик (психически боль- } \\
\text { ной), а не межэтнические отношения...) }\end{array}$ \\
\hline 4. & Махачкала & «Межэтнических проблем у нас нет...» \\
\hline 5. & Махачкала & $\begin{array}{l}\text { «Нет проблем. Единственно - наличие определен- } \\
\text { ных групп лиц, которые пытаются раскачать ситуа- } \\
\text { цию в своих политических целях») }\end{array}$ \\
\hline 6. & Кизлярский район & $\begin{array}{l}\text { «По Дагестану, в общем, кое-где возникают, но в } \\
\text { нашем селе таких проблем нет») }\end{array}$ \\
\hline
\end{tabular}

возможны в соседних населенных пунктах. Многие эксперты так же подтвердили мнение о неактуальности возникновения каких-либо проблем между разными этническими группами в Республике (табл. 2).

6. Вместе с тем, этническая идентичность явно выражена, все четко осознают свою принадлежность к конкретной этно-национальной общности, причем преобладает нормальный тип идентичности с положительным отношением к своей этнической группе, но без преувеличения ее значимости. Распространено мнение об яркой самобытности отдельных дагестанских народов, поэтому возможность их интеграции и образование единой дагестанской нации однозначно отвергается.

Этнические процессы, тем не менее, идут в разных направлениях. С одной стороны, в сельской местности с моноэтничным составом населения наблюдается «этническая диссимиляция», а в полиэтничных городах проявляются интеграционные процессы.

В горных селениях четко выражена локальная территориальная (поселенческая) идентичность населения (чувство места, привязанность к мес- 
Таблица 3

ПРЕДСТАВЛЕНИЯ МЕСТНЫХ ЖИТЕЛЕЙ О ЛОКАЛЬНОЙ ИДЕНТИЧНОСТИ Table 3. Residents' ideas on local identity

\begin{tabular}{|c|c|c|}
\hline № & $\begin{array}{l}\text { Место } \\
\text { интервьюирования }\end{array}$ & Цитаты из интервью \\
\hline & Гуниб & $\begin{array}{l}\text { «Аварцы все разные. Чохцы - очень гордые, со- } \\
\text { гратлинцы - хитрые и прижимистые, а гунибцы - } \\
\text { обладатели сильного и независимого характера... } \\
\text { [подтверждает свою реплику сжатым кулаком]») }\end{array}$ \\
\hline & Куруш & $\begin{array}{l}\text { (3десь живут курушцы, по национальности лезги- } \\
\text { ны)) }\end{array}$ \\
\hline 3. & Согратль & $\begin{array}{l}\text { «...Важнее не дагестанец или аварец, а согратли- } \\
\text { ниц, т.к. у нас богатая история, и мы более объеди- } \\
\text { ненные и имеем свою общину...») }\end{array}$ \\
\hline
\end{tabular}

Таблица 4.

\section{ПРЕДСТАВЛЕНИЯ МЕСТНЫХ ЖИТЕЛЕЙ ОБ ЭТНИЧЕСКОЙ \\ САМОИДЕНТИФИКАЦИИ \\ Table 4. Residents' ideas on ethnic self-identification}

\begin{tabular}{l|l}
\hline $\begin{array}{l}\text { Место } \\
\text { интервьюирования }\end{array}$ & Цитаты из интервью \\
\hline Кубачи & $\begin{array}{l}\text { «Если поеду в Москву назову себя кубачинцем, т.к. даргинцы молодые } \\
\text { [студенты], когда едут в Россию, всегда себя называют кубачинцами. По- } \\
\text { тому что доверие к ним больше, потому что даргинцев много и с разных } \\
\text { регионов, и с разным характером. У акушинцев один характер, у кайтагц- } \\
\text { ев - другой. Кубачинцы никогда не будут участвовать в ненужных делах, в } \\
\text { стычках... К ним больше доверия, и характер хороший. Поэтому некоторые } \\
\text { даргинцы записываются как кубачинцы. Если поеду в Париж назовусь тоже } \\
\text { кубачинцем, т.к. для Парижа или заграницы, если я скажу кубачинец, то } \\
\text { меня лучше поймут, чем даргинца. Кубачи намного известнее, ну может } \\
\text { быть ещё дагестанцев там знают...» }\end{array}$ \\
\hline Согратль & $\begin{array}{l}\text { «..Аварцы делятся, на аварцев, цумадинцев, ахвазцев, ботлихцев. У нас } \\
\text { разные языки, мы вообще друг друга не понимаем») }\end{array}$ \\
\hline
\end{tabular}

ту), которая нередко превалирует над этнической идентификацией. Жители, в первую очередь, позиционируют себя гунибцами, чохцами, согратлинцами, акушинцами, кубачинцами, курушцами и только во вторую - ассоциируют себя с аварцами, даргинцами, лезгинами и лишь потом дагестанцами и россиянами. Они не только осознают свою идентичность, но и придают ей большое субъективное значение (табл. 3).

В отдельных случаях локальная идентичность приобретает прогрессирующий характер, в результате чего формируются субэтнические образования (табл. 4). Яркий пример - кубачинцы не считают себя даргинцами. У них свой, особый образ жизни, язык, этический кодекс. Даже одежда кубачинцев имеет свои отличия, а в традищионном исламе можно заметить черты до- 
исламских верований (маски на свадьбе, праздник «Воды», выбор невесты у родника и т.п.). Кубачинцы - творцы, многовековые навыки художественной обработки металлов живы и передаются от поколения к поколению.

В городах, куда стекаются миграционные потоки с гор, и где сформировался очень пестрый состав населения, наблюдаются процессы межэтнической интеграции (табл. 5).

Выделяются две интеграционные модели: махачкалинская (мультикультурная) и дербентская (симбиотическая).

\section{Махачкалинская модель}

Махачкала - самый крупный город в СКФО. Здесь проживают представители, практически, всех коренных дагестанских народов. По вероисповеданию преобладают мусульмане, но есть и большие православная и еврейская общины. В нулевые годы произошел резкий скачок численности населения. Приток был обусловлен внутренними миграциями из сельской местности. Таким образом, современное население города представлено, в значительно степени, горожанами в первом и втором поколениях, являющихся носителями, преимущественно, сельского образа жизни. Махачкалу можно назвать неким огромным «резервуаром», в котором скапливаются и взаимодействуют большое число разнообразных этнокультурных групп, каждая из которых сохраняет свою этническую память. Значимость общегородской идентичности по сравнению с этнической, понижена. Русский язык широко используется как инструмент межэтнического взаимодействия, но не более. Этнические группы разнообразны, но равноправны в плане слабой укоризненности. Ни у кого нет оснований, да и необходимости в подчеркивании своей исключительности, педалировании этнокультурной исключительности. Нет «главньх» и «второстепенных» народов, нет «хозяев» и «гостей»».

\section{Дербентская модель}

Этническая структура населения Дербента еще более разнообразна, чем в Махачкале. Если в Махачкале преобладают дагестанские народы, то в Дербенте традиционно велика доля азербайджанцев, повышены (несмотря на отрицательные миграции) доли армян и евреев (табл. 6). Здесь на основе многовекового смешения различных культур и этносов в условиях постоянных внешних угроз сформировалось своеобразное городское сообщество, в котором личная этноконфессиональная идентичность подчинена городской принадлежности.

Горожане отмечают свою непохожесть, отстраненность от остального Дагестана (табл. 7). По их мнению, Дербент - это, наверное, единственное место в мире, где не просто мирно живут и общаются азербайджанцы и армяне, евреи, русские и разные северокавказские народы, но образуют уникальное сообщество - «дербентский народ» со своим особым, неторопли- 
ЭТНИЧЕСКАЯ СТРУКТУРА НАСЕЛЕНИЯ МАХАЧКАЛЫ ПО ДАННЫМ ПЕРЕПИСИ 2010 Г.

Table 5. Ethnic structure of Makhachkala population (census, 2010)

\begin{tabular}{lcc}
\hline Этносы & Численность, чел. & Удельный вес, \% \\
\hline 1. 1. Аварцы & 149623 & 26,14 \\
\hline 2. Даргинцы & 88573 & 15,47 \\
\hline 3. Кумыки & 86503 & 15,11 \\
\hline $\begin{array}{l}\text { 4. Лезгины } \\
\text { 5. Лакцы }\end{array}$ & 14,70 \\
\hline $\begin{array}{l}\text { 6. Русские } \\
\text { 7. Табасараны, рутуль- } 29626\end{array}$ & 13,90 \\
\hline $\begin{array}{l}\text { цы. агулы, цахуры и др. } \\
\text { горские этносы }\end{array}$ & 79906 \\
\hline $\begin{array}{l}\text { 8. Другие, недагестанс- } 18572 \\
\text { кие народы }\end{array}$ & 5,14 \\
\hline Всего & \\
\hline & 572076 & 3,24 \\
\hline
\end{tabular}

Составлено по: [3]

вым, с восточным колоритом и чайными посиделками образом жизни. Русский язык - больше, чем инструмент общения, это язык «дербентского народа». Самыми большими ценностями считаются образованность, приверженность собственному укладу жизни, традициям и обычаям, открытость, гостеприимство. По свидетельству старожилов, в 1990- гг. в Дербенте появились полукриминальные группировки «ребят с гор», которые вели себя по-другому. В городе они не прижились - и то ли уехали, то ли ассимилировались, но в настоящее время они не выделяются.

В России довольно широко распространено мнение о том, что Дагестан - один из самых исламизированных регионов страны. Внешне это выглядит действительно так. Огромное количество мечетей, молельных комнат, разнообразные рекламные продукты с цитатами из Корана - повсеместные элементы современных культурных ландшафтов Республики. Во многих поселениях бережно охраняются захоронения выдающихся суфиев - зияраты, которые являются объектами паломничества верующих из других регионов РФ. Однако, в ряде случаев, религиозность носит внешний характер. Многие жители, особенно молодые, говорили о своей причастности к религии не по глубокому убеждению, а потому, что «так надо», «так делают большинс- 
Таблица 6.

ЭТНИЧЕСКАЯ СТРУКТУРА НАСЕЛЕНИЯ ДЕРБЕНТА

ПО ДАННЫМ ПЕРЕПИСИ 2010 Г.

Table 6. Ethnic structure of Derbent population (census, 2010)

\begin{tabular}{|c|c|c|}
\hline \multirow[t]{2}{*}{ Этносы } & \multicolumn{2}{|l|}{ Дербент } \\
\hline & Численность, чел. & Удельный вес, \% \\
\hline 1. Лезгины & 40188 & 33,7 \\
\hline 2. Азербайджанцы & 38523 & 32,3 \\
\hline 3. Табасараны & 18839 & 15,8 \\
\hline 4. Даргинцы & 6692 & 5,6 \\
\hline 5. Русские & 4450 & 3,7 \\
\hline 6. Агулы & 3775 & 3,2 \\
\hline 7. Армяне & 1367 & 1,2 \\
\hline $\begin{array}{l}\text { 8. Горские } \\
\text { евреи/евреи }\end{array}$ & 1345 & 1,1 \\
\hline 9. Рутульцы & 921 & 0,8 \\
\hline $\begin{array}{l}\text { 10. Аварцы, кумыки, } \\
\text { лакцы }\end{array}$ & 1486 & 1.2 \\
\hline 11. Другие народы & 1614 & 1,4 \\
\hline Всего & 119200 & 100 \\
\hline
\end{tabular}

Составлено по: [3]

Таблица 7.

ВЫСКАЗЫВАНИЯ ЭКСПЕРТОВ О ДЕРБЕНТЕ

Table 7. Expert opinion on Derbent

\begin{tabular}{l|l}
\hline $\begin{array}{l}\text { Место } \\
\text { интервыюирования }\end{array}$ & Цитаты из интервью \\
\hline Дербент & $\begin{array}{l}\text { «..Я люблю Дербент не из-за того, что он российс- } \\
\text { кий или табасаранский... Для меня дербентец важ- } \\
\text { нее. Вы нигде в России не найдете такого города. } \\
\text { Море, горы, культура, все родное» }\end{array}$ \\
\hline Дербент & $\begin{array}{l}\text { «Культура дербентцев другая, больше восточная. } \\
\text { Здесь был торговый город, люди мягче, хорошо } \\
\text { общаются. В Махачкале больше горская культура, } \\
\text { другая культура, более грубая...» }\end{array}$ \\
\hline
\end{tabular}


тво», «все горцы должны быть мусульманами», «горцы хотят показать какие они религиозныс» и т.п. Даже посещение мечети превращается иногда в демонстрацию лояльности. Один из молодых образованных людей так выразил свое отношение к исламу: «...к этому надо прийти, чтобы молиться, должна быть в этом потребность. Я пока не готов». Довольно терпимо относятся дагестанцы к внешним атрибутам ислама. Молодежь одевается по-европейски. многие горожанки не носят головные уборы, хиджабы встречаются достаточно редко. Женщины и мужчины вместе находятся на пляжах в обычных купальных костюмах.

Некоторые межэтнические проблемы все же были обнаружены. Условно их можно обозначить как «лакско-чеченская», «кумыкская), «лезгинская» и «русская». Эти проблемы хорошо известны экспертному сообществу [4] Большинство из них связаны не столько с межэтническими, сколько с территориальными и земельными отношениями. Первая из них, наиболее «застарелая» связана с незавершенностью территориальной реабилитации депортированных чеченцев-аккинцев, Процесс тянется более 25 лет, но до сих пор далек от завершения. В настояшее время принята очередная Государственная программа республики Дагестан «Переселение лакского населения Новолакского района на новое место жительства и восстановление Ауховского района» на период 2018-2025 годов [5; 6].

«Кумыкская» проблема спровоцирована земельным конфликтом и переселением горцев на равнинные территории с преобладанием кумыкского населения. Особенно остра проблема в прибрежных пригородах Махачкалы, которые интенсивно застраиваются частными виллами и предприятиями рекреационной инфраструктуры. Проблема активно политизируется и переводится в этническую плоскость идеологами националистического движения «Тенглик», хотя, в данном случае вопрос упирается в правовую неурегулированность земельных отношений.

«Лезгинская» проблема возникла после передачи в 2010-2011 гг. двух анклавных лезгинских аулов Азербайджану и перераспределения водных ресурсов р. Самур, что привело к возмущению местного населения вплоть до проведения протестов [7].

Проблема «Русских» в Дагестане связана с сокращением доли русского населения. Действительно, особенно в 1990-е гг. наблюдались массовые миграции русских, по известны причинам. В настоящее время абсолютное большинство местных жителей жалеют об исходе русских. Несмотря на это проблемы преследования русского населения периодически поднимают в различных публикациях (например, статья Ю. Сошина о снижении роли терских казаков в политической, экономической и общественной жизни Кизляра [8]). В то же время сами казаки из Республиканского казачьего центра в г. Кизляре этого не ощущают, а ведут большую работу по развитию межэтнических и межконфессиональных связей. По их мнению, «в Дагестане казаков уважают». 


\section{Выводы}

1. Многолетний опыт совместного проживания различных в этнокультурном, социальном и конфессиональном отношениях групп населения позволил выстроить в Дагестане уникальную систему продуктивного межэтнического взаимодействия.

2. Состояние этнических процессов характеризуется проявлением интеграционных и дезинтеграционных тенденций. В сельских моноэтнических сообществах происходит дробление единого этноса на локальные поселенческие идентичности. Городские сообщества испытывают интеграционное развитие. Установлено два типа интеграционных моделей: мультикультурная, махачкалинская и «симбиотическая» дербентская,

3. Религиозность в современном Дагестане приобретает демонстративно-поведенческий характер, появились группы людей, для которых значимость религиозных убеждений в системе ценностей уходит на второй план.

4. Этнические проблемы в Дагестане не редко являются следствием непродуманных или ошибочных управленческих решений местных и федеральных властей и отсутствием взвешенной национальной политики.

\section{Библиографический список}

1. Тишков В., Степанов В. Россия в этническом измерении // Haселение и общество. Информационный бюллетень Центра демографии и экологии человека Института народохозяйственного прогнозирования РАН. М., 2004. №81.

2. Итоги Всероссийской переписи населения 2010 года в отношении демографических и социально-экономических характеристик отдельных национальностей. Приложение 2 (Национальный состав населения по субъектам Российской Федерации) URL: http://www.gks.ru/free_doc/new_site/perepis2010/croc/resuIts2. html (дата обращения: $\overline{30}$.10.2018)

3. Итоги Всероссийской переписи населения 2010г. Т. 3: Национальный состав и владение языками, гражданство / Территориальный орган федеральной службы госстатистики по Республике Дагестан. Махачкала, 2013. 474 c.

4. Межэтнические и конфессиональные отношения в Северо-Кавказском федеральном округе. Экспертный доклад / Под ред В.А. Тишкова, В.В. Степанова. М., 2013. 98 с.

5. Государственная программа Республики Дагестан «Переселение лакского населения Новолакского района на новое место жительства и восстановление Ауховского района» (2018- 
2025). http://docs.cntd.ru/document/450357432 (дата обращения 30.10.2018).

6. Мудуев Ш.С. Социально-экономические последствия вынужденных миграций населения (Новолакский район Республики Дагестан) // Миграционные процессы: проблемы адаптации и интеграции мигрантов: сб. материалов IV Международной научно-практической конференции / под ред. В.С. Белозерова Ставрополь, 2018. С. 80-87.

7. Дагестанские села передали Азербайджану вместе с жителями (18.06.2013 г.). URL: http://flnka.ru/digest-analytics/2785dagestanskie-sela-peredali-azerbaydzhanu-vmeste-s-zhitelyami. html (дата обращения: 30.10.2018).

8. Сошин Ю. Дерусификация северного Дагестана в свете кизлярского расстрела. URL: https://terskiykazak. livejournal.com/913691. html (дата обращения: 30.10.2018).

\section{References}

1. Tishkov V., Stepanov V. Russia in the Ethnic Dimension // Population and Society. Newsletter of the Center for Demography and Human Ecology, Institute for National Economic Forecast at the Russian Academy of Sciences. M., 2004. \#81.

2. The results of the Russian National Census (2010) in relation to the demographic and socio-economic specifics of individual ethnicities. Appendix 2 (National composition of the population by regions of the Russian Federation). URL: http://www.gks.ru/free_doc/new_ site/perepis 2010/croc/results2. html (referral date: 10/30/2018)

3. The results of the Russian National Census (2010), Volume 3: National composition and language proficiency, citizenship / Territorial body of the Federal State Statistics Service for the Republic of Dagestan. Makhachkala, 2013. 474 p

4. Interethnic and confessional relations in the North-Caucasus Federal District. Expert Report / Ed. V.A. Tishkova, V.V. Stepanova. M. 2013. 98 p.

5. The state program of the Republic of Dagestan "Relocation of the Laki population of the Novolaksky district to a new place of residence and restoration of the Aukhovsky district" (2018-2025). http:// docs.cntd.ru/document/450357432 (referral date: 10/30/2018).

6. Muduev Sh.S. Socio-economic effects of forced migration (Novolaksky district of the Republic of Dagestan) // Migration processes: problems of adaptation and integration of migrants: Volume of the IV International Research Conference / ed. V.S. Belozerov. Stavropol, 2018. p. 80-87.

7. Dagestani villages given to Azerbaijan together with residents (06/18/2013). URL: http://flnka.ru/digest-analytics/2785-dagestanskie-sela-peredali-azerbaydzhanu-vmeste-s-zhitelyami.html (referral date: 30.10.2018)

8. Soshin Yu. Derusification of Northern Dagestan in the light of the Kizlyar massacre. URL: https://terskiykazak.livejournal.com/913691 html (access date: 10/30/2018). 


\section{6 авторах}

1. Щитова Наталия Александровна, доктор географических наук профессор кафедры социально-экономической географии, геоинформатики и туризма Северо-Кавказского федерального университета. Телефон: (905)466-91-20; E-mail: stavgeo@mail $\mathrm{ru}$.

2. Соловьев Иван Алексеевич, кандидат географических наук, доцент кафедры социально-экономической географии, геоинформатики и туризма Северо-Кавказского федерального университета. Телефон: (905)415-56-24; E-mail: soloivan@mail.ru.

3. Белозеров Виталий Семенович, доктор географических наук, профессор кафедры социально-экономической географии, геоинформатики и туризма Северо-Кавказского федерального университета. Телефон: (962)451-77-88; E-mail: vsbelozerov@ yandex.ru.

\section{About the authors}

1. Schitova Natalia Aleksandrovna, Doctor of Geographical Sciences, NCFU. Phone: (905)466-91-20; E-mail: stavgeo@mail.ru.

2. Soloviev Ivan Alekseevich, Candidate of Geographical Sciences Associate Professor, NCFU. Phone: (905)415-56-24; E-mail soloivan@mail.ru.

3. Belozerov Vitaly Semenovich, Doctor of Geographical Sciences, NCFU. Phone: (962)451-77-88; E-mail: vsbelozerov@yandex.ru. 